\title{
PELANGGARAN PRINSIP KERJA SAMA PADA DIALOG ANTARTOKOH DALAM NOVEL KOALA KUMAL KARYA RADITYA DIKA
}

\author{
Erlik Fauziyah \\ SMP Ma'arif Panceng Kabupaten Gresik \\ pos-elerlikfauziyah79@gmail.com \\ Syamsul Ghufron \\ Universitas Islam Darul Ulum Lamongan \\ syamsulghufron@unisda.ac.id
}

\begin{abstract}
Abstrak: Penelitian ini bertujuan untuk mendeskripsikan jenis-jenis pelanggaran prinsip kerja sama pada dialog antartokoh dalam novel Koala Kumal karya Raditya Dika. Penelitian ini menggunakan metode deskriptif kualitatif.Sumber data penelitian ini berupa novel Koala Kumal karya Raditya Dika yang terdiri atas 12 cerita.Teknik pengumpulan data yang digunakan meliputi teknik membaca, menyimak, dan mencatat. Instrumen penelitian yang digunakan berupa indicator prinsip kerja sama dalam bentuk tabel. Teknik analisis data dengan metode deskriptif kualitatif dengan langkah mengumpulkan data, reduksi data, penyajian data, dan penarikan simpulan.Hasil penelitian ini menunjukkan dua simpulan. Pertama, bentuk pelanggaran prinsip kerja sama yang terjadi yaitu (1) maksim kuantitas, (2) maksim kualitas, (3) maksim relevansi, dan (4) maksim cara atau pelaksanaan. Kedua, yaitu tiga tujuan dari pelanggaran prinsip kerja sama, yaitu (1) tujuan representatif: memberikan informasi atau memberi penjelasan, memastikan, menyatakan harapan, dan menegaskan, (2) tujuan direktif: menyindir, mengejek, memberikan saran, dan mengkritik atau protes, dan (3) tujuan ekspresif: berbohong, menyombongkan diri, menyatakan tidak suka, menyatakan prihatin, merayu atau menggoda, memuji, bingung, dan menciptakan humor.
\end{abstract}

Kata kunci: prinsip kerja sama, maksim, representatif, direktif, ekspresif

Abstract: This study aims to describe the types of violations of the principle of cooperation in dialogue between groups in the novel Koala Kumal by Raditya Dika. This study used descriptive qualitative method. The data source of this research is Raditya Dika's Koala Kumal novel which consists of 12 stories. Data collection techniques used include techniques for reading, listening, and taking notes. The research instrument used was a cooperative principle indicator in the form of a table. Data analysis techniques with qualitative descriptive methods with steps to collect data, data reduction, data presentation, and drawing conclusions. The results of this study show two conclusions. First, the form of violation of the principle of cooperation that occurs is (1) the maxim of quantity, (2) the maxim of quality, (3) the maxim of relevance, and (4) the maxim of the method or implementation. Second, namely the three objectives of violating the principle of cooperation, namely (1) representative purpose: providing information or giving explanations, ensuring, expressing expectations, and affirming, (2) directive objectives: insinuating, mocking, giving advice, and criticizing or protesting, and (3) expressive goals: lying, boasting, 
expressing dislike, expressing concern, seducing or teasing, praising, confused, and creating humor.

Keywords: the principle of cooperation, maxim, representative, directive, expressive

\section{PENDAHULUAN}

Bahasa sangat dibutuhkan untuk menjalin adanya suatu komunikasi antarindividu maupun kelompok. Bahasa merupakn media untuk menyampaikan suatu makna kepada orang lain baik secara lisan maupun tertulis. Bahasa menjadi salah satu alat yang paling utama dan penting, terlebih karena manusia merupakan makhluk social dan memerlukan interaksi yang berupa komunikasi dengan orang lain. Hal tersebut menjadikan komunikasi sebagai salah satu factor yang mendukung dalam kehidupan bermasyarakat dan sarana penyampaian informasi, sehingga agar suatu informasi atau pesan dapat tersampaikan dengan baik, maka informasi yang disampaikan harus jelas, sesuai dengan kebenaran, sesuai dengan kebutuhan tidak merubah pesan dan sebagainya.

Komunikasi selalu diasosiasikan dengan proses berbahasa, sebaliknya apabila berbicara tentang bahasa, selalu dikaitkan dengan komunikasi. Komunikasi selalu dikaitkan dengan bahasa, bahkan sering dianggap bahwa bahasa adalah komunikasi, karena pada kenyataannya system tanda yang paling prinsipil dalam komunikasi manusia adalah bahasa.Dari pengertian bahasa tersebut dapat disimpulkan bahwa fungsi utama bahasa adalah sebagai alat komunikasi. Selain itu bahasa juga mempunyai fungsi yang lain yaitu (1) untuk menyatakan ekspresi diri, (2) sebagai alat untuk mengadakan interaksi dan adaptasi social, dan (3) sebagai alat untuk mengadakan control social (Keraf, 1984:4).
Menurut Soedjoko (dalam Suhadi, 1989:38), humor memang bisa berfungsi untuk melaksanakan segala keinginan dan segala tujuan di segala bidang.Humor dapat menyadarkan orang bahwa dirinya tidak selalu benar.Humor dapat mengajar orang melihat persoalan dari berbagai sudut.Humor dapat menghibur, humor dapat melancarkan pikiran, humor dapat membuat orang mentolelir sesuatu.Humor dapat membuat orang memahami soal pelik.Untuk mencapai funsi-fungsi humor tersebut orang yang berhumor harus mnggunakan tindak tutur yang berbeda dengan tindak tutur lainnya, yaitu tindak tutur khusus humor.

Dunia hiburan di Indonesia beberapa tahun terakhir ini semakin diramaikan dengan kehadiran jenis hiburan komedi terbaru. Di antara para comic kenamaan di Indonesia salah satu nama yang patut diperhitungkan memiliki kapasitas sebagai komik dengan materi yang paling digemari oleh para remaja di Indonesia adalah Raditya Dika. Ia memulai kiprahnya sebagai comic dengan terlebih dahulu menjadi seorang blogger (penulis blog) semasa ia menempuh studi di Australia. Blognya yang diisi dengan kisah pengalaman pribadinya yang sebagian besar menceritakan segala bentuk kebodohan dan kekonyolan yang ia lakukan. Sebagian besar isi blognya tersebut ia bukukan dan laku di pasaran. Dari sekian buku-buku yang ia terbitkan dua diantaranya telah difilmkan yakni kambing Jantan dan Cinta Brontosaurus. Ia juga membuat serial komedi yang ditayangkan di kompas TV dengan judul Malam Minggu Miko. Serial inipun juga menjadi sedemikian popular dan 
difilmkan dengan judul Cinta Dalam Kardus.Dari kacamata linguistic, hampir seluruh materi blog, buku dan filmya merupakan wujud dari pelanggaran prinsip kerja sama yang justru menghadirkan kelucuan yang khas. Pola yang sama juga hadir di karyanya yang berjudul "Koala Kumal".

Adanya tuturan-tuturan dalam dialog antartokoh dalam novel Koala Kumal karya Raditya Dika menunjukkan terjadinya kegiatan berkomunikasi antara penutur dan mitra tutur. Dalam berkomunikasi, terkadang mitra tutur menanggapi atau memberikan pernyataan yang tidak sesuai atau tidak relevan dengan topik pembicaraan yang dimaksudkan oleh penutur.Selain itu, ada pula peserta tutur yang memberikan tanggapan atau jawaban yang berlebihan, memberikan informasi yang tidak benar ataupun tidak berdasarkan fakta yang ada, dan juga memberikan informasi yang ambigu. Hal itu merupakan fenomena pelanggaran prinsip kerja sama yang terjadi pada dialog antartokoh dalam novel Koala Kumal karya Raditya Dika .Pelanggaran tersebut dapat terjadi karena adanya tujuan-tujuan tertentu yang sengaja dilakukan oleh peserta tutur.

Kasus pelanggaran prinsip kerja sama dalam dialog antartokoh dalam novel Koala Kumal menunjukkan bahwa dalam komunikasi membutuhkan sarana yang mengatur supaya komunikasi berjalan dengan komunikatif, efektif, dan efisien. Sarana yang dimaksudkan adalah dengan berdasar kepada empat maksim dalam prinsip kerja samayang dikemukakan oleh Grice (dalam Chaer, 2010: 34), yaitu maksim kuantitas, maksim kualitas, maksim relevansi (hubungan), dan maksim cara (pelaksanaan).

Maksim kuantitas menghendaki agar peserta tutur harus seinformatif mungkin dan tidak berlebihan dalam memberikan informasi yang dibutuhkan oleh mitra tutur.Maksim kualitas menghendaki peserta tutur agar tidak mengatakan sesuatu yang tidak sesuai dengan faktanya.Maksim relevansi menghendaki agar peserta tutur diharapkan relevan terhadap informasi yang diberikan sesuai dengan topik percakapan. Maksim caraatau pelaksanaan menghendaki peserta tutur dalam berkomunikasi memberikan informasi yang jelas, dan tidak ambigu. Penaatan prinsip kerja sama terjadi jika peserta tutur mematuhi maksim-maksim prinsip kerja sama. Sebaliknya, apabila dalam bertutur tidak sesuai dengan aturan maksim-maksim dalam prinsip kerja sama, percakapan tersebut dinyatakan melanggar prinsip kerja sama.

Dialog antartokoh dalam novel Koala Kumal karya Raditya Dika merupakan novel yang kocak atau bertajuk komedi sehingga pembaca dibuat tertawa sendiri oleh raditya Dika. Koala Kumal adalah novel komedi yang menceritakan pengalaman Raditya Dika dari mulai jurit malam SMP yang berakhir kekacauan sampai bertemu perempuan yang mahir bermain tombak. Seluruh cerita di dalamnya berasal dari kisah nyata. Sehingga cerita yang disajikan oleh Raditya Dika digemari dan menjadi salah satu bacaan komedi yang menarik. Selain menyajikan tema-tema yang unik dan juga inspiratif setiap episodenya. Tentu saja protes serta kritikan disampaikan peserta tutur dalam dialog antartokoh dalam novel Koala Kumal dengan cara gaya humor (banyolan), supaya menghindari kesalahfahaman yang akan terjadi dan juga tidak menyinggung perasaan yang bersangkutan.

Pelanggaran prinsip kerja sama dapat juga terjadi karena adanya tujuan tertentu, misalnya untuk melucu supaya situasi tidak terlalu beku. Misalnya, penutur sedang mengungkapkan rasa 
sedih karena terkena musibah terhadap mitra tutur, dengan harapan mitra tutur dapat mengetahui kesedihan yang sedang dirasakan oleh penutur. Namun, karena mitra tutur merasa pembicaraan yang sedang berlangsung itu terlalu serius, dia mencoba untuk mengalihkan perhatian kepada masalah lain yang lucu atau jenaka supaya penutur merasa terhibur dan melupakan kesedihan yang sedang dirasakannya. Kasus tersebut dapat digolongkan ke dalam pelanggaran maksim relevansi, yaitu penutur menanggapi sesuatu tetapi menyimpang dari masalah yang sedang dibicarakan.

Dalam tuturan atau dialog antartokoh dalam novel Koala Kumal karya Raditya Dika, setiap pelanggaran prinsip kerja sama yang terjadi memiliki tujuan maupun alasan tertentu yang ingin disampaikan oleh penutur maupun mitra tutur. Empat pelanggaran prinsip kerja sama dalam novel yang berjudul Koala Kumal berupa maksim kuantitas, maksim kualitas, maksim relevansi, dan maksim cara (pelaksanaan), yang masingmasing memiliki tujuan yang ingin disampaikan oleh peserta tutur. Adapun tujuan tersebut antara lain berupa tindak representatif, tindak direktif, dan tindak ekspresif. Selain menemukan tujuan dari pelanggaran prinsip kerja sama yang terjadi dalam dialog antartokoh dalam novel Koala Kumal, alasan mengapa peneliti memilih novel komedi yang berjudul Koala Kumal karena novel tersebut ditemukan fenomena kebahasaan yang berkaitan dengan ilmu pragmatik, yaitu berupa pelanggaran prinsip kerja sama serta tujuan dari bentuk pelanggaran yang terjadi dalam dialog antartokoh pada novel komedi yang berjudul Koala Kumal karya Raditya Dika.

Berdasarkan paparan di atas, maka perlu adanya penelitian yang bertujuan untuk (1)Mendeskripsikan bentuk pelanggaran maksim kuantitas dalam dialog antartokoh dalam novel Koala Kumal karya Raditya Dika, (2) Mendeskripsikan bentuk pelanggaran maksim kualitas dalam dialog antartokoh dalam novel Koala Kumal karya Raditya Dika, (3) Mendeskripsikan bentuk pelanggaran maksim relevansi dalam dialog antartokoh dalam novel Koala Kumal karya Raditya Dika, dan (4) Mendeskripsikan bentuk palanggaran maksim cara dalam dialog antartokoh dalam novel Koala Kumal karya Raditya Dika.

\section{METODE PENELITIAN}

Penelitian ini tergolong penelitian deskriptif kualitatif. Data dikumpulkan dengan teknik dokumentasi, simak, dan catat.

Teknik analisis data penelitian ini menggunakan teknik analisis data kualitatif yang dikembangkan oleh Milles dan Huberman (dalam Ratna 2010:309311) yaitu dimulai dengan mengumpulkan data, reduksi data, penyajian data, dan penarikan simpulan.Teknik analisis data terkandung dalam tiga tahap terakhir, yaitu reduksi data, penyajian data, dan penarikan simpulan.

\section{HASIL PENELITIAN}

Tahap ini dilakukan untuk menemukan jawaban-jawaban yang berhubungan dengan perumusan masalah. Pembahasan dalam penelitian ini meliputi (1) jenis pelanggaran prinsip kerja sama dalam dialog antartokoh dalam novel Koala Kumal karya Raditya Dika dan (2) tujuan pelanggaran prinsip kerja sama dalam dialog antartokoh dalam novel Koala Kumal karya Raditya Dika.

Berdasarkan penelitian yang telah dilakukan, ditemukan 45 tuturan yang melanggar prinsip kerjasama. Tuturan tersebut digolongkan atas, 11 tuturan 
dengan melanggar maksim kuantitas, 8 tuturan yang melanggar maksim kualitas, 12 tuturan yang melanggar maksim relevansi, dan 14 tuturan yang melanggar maksim cara atau maksim pelaksanaan. Setiap bentuk maupun macam-macam pelanggaran prinsip kerja sama pasti mempunyai tujuan yang mendukung terjadinya pelanggaran tersebut, tujuannya yaitu (a) tujuan tindak representative, (b) tujuan tindak direktif, dan (c) tujuan tindak ekspresif. Tujuantujuan pelanggaran tersebut dilakukan semata-mata ingin menghibur dan membuat penonton tertawa.

\section{PEMBAHASAN}

\section{Pelanggaran Maksim Kuantitas}

Maksim kauntitas menghendaki setiap peserta percakapan memberikan memberikan kontribusi yang secukupnya atau sebanyak yang dibutuhkan oleh lawan tuturnya. Dalam memberikan informasi yang wajar, jangan terlalu sedikit dan jangan pula terlalu berlebihan, dalam memberikan kontribusi yang dibutuhkan.Jadi, peserta tutur diharapkan jangan berlebihan dalam memberikan informasi (Wijana, 1996:46).

\section{Pelanggaran Maksim Kuantitas dengan Tujuan Tindak Representatif}

Contoh dialog yang melanggar maksim kuantitas dengan tujuan tindak representatif dengan alasan pelanggaran berupa memberikan penjelasan adalah sebagai berikut:

"Aku gak mau kamu tahu dari orang lain. Jadi gini, aku sekarang udah jadian sama Astra."

Gak ada respons yang baik yang dapat gue keluarkan selain, "Oh gitu."

"Iya."Kata dia. "Kamu baik-baik, ya."

Lalu, telepon ditutup.

Terus terang gue bingung kenapa Deska jadian sama Astra.

(Dika, 2015:67)

\section{Pelanggaran maksim kuantitas dengan tujuan tindak direktif}

Contoh lain dialog yang melanggar maksim kuantitas dengan tujuan tindak direktif dengan alasan pelanggaran berupa menyindir akan dipaparkan pada kutipan berikut:

"Mama malu, Dika! Kok dialog Mama gak kau buat bagus-bagus gitu? Kenapa gak ada kata-kata mutiaranya? Bikin Mama kelihatan baik hati banget, dong, kayak di sinetron gitu! Kamu bisa bikin film gak, sih?!"

"Tapi, Ma..."

"kamu siap-siap di rumah, ya! Mama sebentar lagi pulang! Kita bahas ini semua!"

(Dika, 2015:44)

\section{Pelanggaran Maksim Kuantitas dengan Tujuan Tindak Ekspresif}

Contoh tuturan yang melanggar maksim kuantitas dengan tujuan tindak ekspresif dengan alasan pelanggaran berupa permintaan maaf.

"Jadi kapan kita pergi pacaran, nih?" gue jawab, "kalau naskahnya udah rapi, ya."

“Kapan rapinya?Kok gak rapi-rapi?!’Tanya dia.

"Gue jawab, "Nomor yang anda hubungi sedang tidak aktif."

"Uh...Operator telepon yang kayak gitu seharusnya suara cewek," kata dia.

"Oh, iya," kata gue. "Ya, udah maaf, ya, aku gak bisa malam mingguan lagi.

(Dika, 2015:3)

\section{Pelanggaran Maksim Kualitas}

Maksim kualitas menghendaki agar peserta komunikasi hendaknya mengatakan sesuatu yang sebenarnya, yang sesuai dengan fakta, kecuali jika ia tidak tahu. Jadi peserta tutur jangan mengatakan apa yang diyakini salah, jangan mengatakan sesuatu yang belum cukup bukti (Wijana, 1996:48).

\section{Pelanggaran Maksim Kualitas dengan Tujuan tindak representative}

Contoh tuturan yang melanggar maksim kualitas dengan tujuan tindak representative dengan alasan pelanggaran berupa mencurahkan isi hati adalah sebagai berikut.

"Gue udah sering ngajak dia nonton.Gue bayarin.Dia suka kucing, gue sampek belajar gimana caranya ngelatih kucing dia. Eh, begitu gue tembak, dia langsung nolak gue mentah-mentah.Katanya gue lebih cocok jadi temen." 
"Itu alasan yang diapakai cewek kalau mereka gak enak nolak cowok, " kata gue.

"Gue masih jombloh, nih, Dit."

"sampai sekarang?"

(Dika, 2015:238)

\section{Pelanggaran Maksim Kualitas dengan Tujuan tindak direktif}

Contoh tuturan yang melanggaran maksim kualitas dengan tujuan tindak direktif dengan alasan pelanggaran berupa sindiran akan dipaparkan sebagai berikut.

Deska nanya, "Emang loh gak pernah lari sore?"

"Lo biasa lari di mana?"

"Uh, di... sekitar kompleks aja," kata gue, berbohong agar tidak kelihatan cemen.

(Dika, 2015:56)

\section{Pelanggaran Maksim Kualitas dengan Tujuan Tindak Ekspresif}

Contoh tuturan yang melanggar maksim kualitas dengan tujuan tindak ekspresif dengan alasan pelangggaran berupa berbohong (menyatakan hal yang tidak benar) adalah sebagai berikut

"Lho mana petasannya?" Tanya Bahri

"Gue gak jadi beli petasannya Ri," kata gue berbohong. "Terus?"

"Gue gak ikutan lagi, deh, main petasan.Takut kualat" "Jadi? Lo gak ikut malam ini?" Bahri terlihat kesal. "Segini doang pertemanan kita"

(Dika, 2015:238)

\section{Pelanggaran Maksim Relevansi}

Maksim relevansi adalah maksim yang mengharuskan setiap peserta pertuturan memberikan konribusi yang relevan dengan masalah yang sedang dibicarakan (Wijana, 1996:49).

\section{Pelanggaran Maksim Relevansi dengan Tujuan Tindak Representative}

Contoh tuturan yang melanggar maksim relevansi dengan tujuan representative dengan alasan pelanggaran berupa memberikan informasi atau menjelaskan adalah sebagai berikut.

"Jangan melihara anjing, Bang," kata pembantu gue.

"Kenapa, Mbak?"

"Nih, ya, Mbak kasih tahu.Kalau kita memelihara anjing, malaikat gak bisa masuk ke rumah, nanti Mbak gak bisa masuk rumah, dong!" kata si Mbak mesammesem.

(Dika, 2015:85)

\section{Pelanggaran Maksim Relevansi dengan Tujuan Tindak Direktif}

Contoh tuturan yang melanggar maksim relevansi dengan tujuan direktif dengan alasan pelanggaran berupa memberi saran adalah sebagai berikut.

"Dika, kamu mau main layangan?" "Iya.Kenapa emang Ma?" Tanya gue

"Udah pakai sunbklock belum?” Tanya Nyokap

"Ma, mana ada anak cowok main layangan pakai sunblock? Cemen banget!"

"Duh Dika, nanti kalo kulit kamu gosong, kamu jadi item, loh." (Dika, 2015:3)

\section{Pelanggaran Maksim Relevansi dengan Tujuan Tindak Ekspresif}

Berikut ini adalah contoh tuturan yang melanggar maksim relevansi dengan tujuan tindak ekspresif dengan alasan permintaan maaf.

"Jam berapa ini?!"

"Maaf-maaf," katanya.

(Dika, 2015: 66)

\section{Pelanggaran Maksim Cara atau Maksim Pelaksanaan \\ Maksim cara mengharuskan} penutur dan mitra tutur berbicara secara langsung, tidak kabur, tidak berbelit-belit, harus jelas, tidak ambigu, tidak berlebihlebihan, dan teratur (wijana, 1996:60)

\section{Pelanggaran Maksim Cara atau Pelaksanaan dengan Tujuan Tindak Representatif}

Tuturan yang melanggar maksim cara atau pelaksanaan dengan tujuan tindak representatif dengan alasan pelanggaran berupa permintaan ketegasan maksud tuturan.

"Jadi, pacar kamu yang mau datang ini cantik gak?"

"Emang kenapa, Ma?" Tanya Gue

"Kalau jelek mau Mama racunin!” Seru Nyokap

"Ma!" teriak gue.

"Dika, kita harus melanjutkan keturunan keluarga kita dengan baik!muka kamu kan, seadanya, nanti kalau kamu kawin sama orang jelek anaknya gimana?" (Dika, 2015:32) 
Pelanggaran Maksim Cara atau Pelaksanaan dengan Tujuan Tindak Direktif

Contoh tuturan yang melanggar maksim maksim cara atau pelaksanaan dengan tujuan tindak direktif dengan alasan pelanggaran berupa tindak menyampaikan saran.

"Papa terus terang kecewa, Dika."

"Kecewa kenapa, Pa?"

Bokap memukul meja sambil mengangkat alisnya.

Lalu ia berseru, "KENAPA PELEM KAU GAK ADA ADEGAN CIUMANNYA?!”

\section{Pelanggaran Maksim Cara atau Pelaksanaan dengan Tujuan Tindak Ekspresif}

Contoh tuturan yang melanggar maksim cara atau pelaksanaan dengan tujuan tindak ekspresif dengan alasan pelanggaran berupa menyampaikan rasa yang membingungkan.

"Ya, Pa?" Tanya gue, berusaha menyembunyikan rasa takut. "Jadi begini, Dika," kata Bokap. "Papa sudah nonton film kau barusan." "Terus?" Tanya gue. "Kita ketemuan, " kata Bokap, singkat. "Di rumah?'"Enggak.Kita ketemuan di luar rumah saja." "Di...laur...rumah?"Tanya gue. "Iya.Kita bahas film kau." "Hah? Serius, Pa?" Tanya gue panic. "Iya," kata Bokap, nadanya kalem. (Dika, 2015: 40-41)

\section{SIMPULAN DAN SARAN}

Berdasarkan paparan hasil penelitian dan analisis data mengenai pelanggaran prinsip kerja sama dalam dialog antartokoh dalam novel Koala Kumal Karya Raditya Dika, maka simpulan yang diperoleh adalah sebagai berikut.

Terdapat bentuk pelanggaran prinsip kerja sama dalam dialog antartokoh dalam novel Koala Kumal karya Raditya Dika. Bentuk pelanggaran prinsip kerja sama dalam dialog antartokoh dalam novel Koala Kumal karya Raditya Dika terdiri atas (a) pelanggaran maksim kuantitas dengan data sebanyak 11 data (b) pelanggaran maksim kualitas sebanyak 8 data (c) pelanggaran maksim relevansi sebanyak 12 data (d) pelanggaran maksim cara atau pelaksanaan sebanyak 14 data. Pelanggaran terbanyak terdapat pada maksim cara atau maksim pelaksanaan dengan data sebanyak 14 data, sedangkan pelanggaran paling sedikit terdapat pada pelanggaran maksim kualitas.

Adapun tujuan pelanggaran prinsip kerja sama terjadi, yaitu (a) tujuan tutur tindak representatif dengan alasan pelanggaran berupa: memberikan informasi atau memberi penjelasan, memastikan, menyatakan harapan, dan menegaskan;(b) tujuan tutur tindak direktif dengan alasan pelanggaran berupa: menyindir,mengejek, memberikan saran, dan mengkritik atau protes; dan (c) tujuan tutur tindak ekspresif dengan alasan pelanggaran berupa: berbohong, menyombongkan diri, menyatakan tidak suka, menyatakan prihatin, merayu atau menggoda, memuji,bingung, dan menciptakan humor. Pelanggaran prinsip kerja sama tersebut disebabkan adanya tujuan tujuan tertentu dari peserta tutur dan karena adanya sebuah konteks epistemis, yaitu pemahaman bersama yang dimiliki antarpeserta pertuturan.Selain terdapat tujuan tertentu dan konteks, adapula faktor lain yang mempengaruhi pelanggaran maksim yang terjadi, yaitu faktor kedekatan antara penutur dan mitra tutur.

Berkaitan dengan pelanggaran prinsip kerja sama dalam dialog antartokoh dalam novel Koala Kumal Karya Raditya Dika, berdasarkan simpulan dan implikasi, dapat disarankan sebagai berikut

Peserta pertuturan hendaknya mengindahkan maksim-maksim prinsip kerja sama supaya komunikasi berjalan lancar, yaitu dengan menaaPeserta pertuturan hendaknya mengindahkan maksim-maksim prinsip kerja sama supaya komunikasi berjalan lancar, yaitu dengan menaatiempat maksim (maksim 
kuantitas, maksim kualitas, maksim relevansi, maksim cara).

\section{DAFTAR PUSTAKA}

Alwasilah, Chaedar.1993. Pengantar Sosiologi Bahasa. Bandung: Angkasa.

Bungin, Burhan. 2009. Penelitian Kualitatif. Jakarta: Kencana.

Chaer, Abdul dan Leonie Agustina.2004. Sosiolinguistik Perkenalan Awal (Revisi.Ed).Jakarta: Rineke Cipta.

Chaer, Abdul. 2010. Kesantunan Berbahasa. Jakarta: Rineka Cipta.

Dardjowidjojo, Soejono. 2003. Psikolinguistik: Pemahaman Bahasa Manusia. Jakarta: Yayasan Obor Indonesia.

Djadjasudarma, Dr. T. Fatimah. 1993. Metode Linguistik: Ancangan Metode Penelitian dan Kajian. Bandung: PT Eresco Anggota IKAPI.

Enre, Fachruddin Ambo.1988. DasarDasar Keterampilan menulis. Jakarta: P2LPTK.

Firmansyah, Anand. 2011. "Penyimpangan Prinsip Kerjasam dan Prinsip Kesopanan dalam Wacana Humor Verbal Tulis Mang Kuteng”.tesis. Yogyakarta: Progam Studi Bahasa dan Sastra Indonesia, FBS Universitas Negeri Yogyakarta.

Keraf, Gorys. 1980. Tata Bahasa Indonesia. Ende Flores. Nusa Indah.

Leech, Geoffrey. 1993. Prinsip-prinsip Pragmatik.Jakarta: Universitas Indonesia.
Moleong, Lexy J. 2001. Metodologi Penelitian Kualitatif. Bandung: PT Remaja Rosdakarya.

Nababan, PWJ. 1987. Ilmu Pragmatik (Teori dan Penerapannya). Jakarta: Departemen Pendidikan dan Kebudayaan. Nadar, FX. 2009. Pragmatik dan Penelitian Pragmatik- (Edisi Pertama). Yogyakarta: Graha Ilmu.

Pangaribuan, Tagor. 2008. Paradigma Bahasa. Yogyakarta: Graha Ilmu.

Ratna, Nyoman Kutha. 2010. Metodologi Penelitian: Kajian Budaya dan Humaniora pada Umumnya. Yogyakarta: Pustaka Pelajar.

Suhadi, M. Agus. 1992. Humor itu Serius: Pengantar Ilmu Humor. Jakarta: PT. Pustaka Karya: Grafikatama Jaya.

Wijana, I Dewa Putu. 1996. Dasar-dasar Pragmatik. Yogyakarta: Andi. 